\title{
A PERCEPÇÃO SOBRE AS TECNOLOGIAS DE AUTO- ATENDIMENTO E TRABALHO EM BIBLIOTECAS UNIVERSITÁRIAS
}

https://dx.doi.org/10.5902/2318133867813

\author{
Bárbara Rocha Bittencourt ${ }^{1}$ \\ Isaías Scalabrin Bianchi²
}

\begin{abstract}
Resumo
Neste texto, apresenta-se a análise da percepção do corpo técnico de bibliotecas universitárias, sobre a aceitação da tecnologia de autoatendimento e o papel social do trabalho nas bibliotecas universitárias. Por meio de uma metodologia qualitativa, com aplicação de questionários, as percepções dos servidores são discutidas diante do arcabouço teórico. A análise dos dados revelou elevada percepção sobre as utilidades do autoatendimento pela autonomia, praticidade e privacidade promovidas pela tecnologia, os fatores motivacionais para o uso dessa tecnologia, e os seus principais usuários. Além disso, são discutidas as percepções sociais relacionadas ao trabalho, devido as implicações das tecnologias de autoatendimento no contexto do neoliberalismo e da substituição e alocação da força de trabalho.

Palavras-chave: tecnologias; autoatendimento; bibliotecas.
\end{abstract}

\section{THE PERCEPTION ABOUT SELF-SERVICE TECHNOLOGIES AND WORK IN UNIVERSITY LIBRARIES}

\section{Abstract}

This manuscript analyzes the perception of university library staff about the acceptance of selfservice technology and the social role of work in university libraries. Through a qualitative methodology, with application of questionnaires, the perceptions of public servants are discussed about of the theoretical framework. Data analysis revealed a high perception about the self-service utilities due to the autonomy, practicality and privacy promoted by the technology, the motivational factors for the use of this technology, and its main users. In addition, social perceptions related to work are discussed due to the implications of self-service technologies in the context of neoliberalism and the substitution and allocation of the workforce.

Keywords: technologies; self-service; libraries.

${ }^{1}$ Instituto Federal do Paraná, Brasil. E-mail: barbararb@gmail.com.

2 Universidade Federal de Santa Catarina, Brasil. E-mail: isaias.bianchi@ufsc.br.

\begin{tabular}{|l|l|l|c|c|c|}
\hline Regae: Rev. Gest. Aval. Educ. & Santa Maria & v. 11 & n. 20 & e67813, p. 1-14 & 2022 \\
\hline
\end{tabular}




\section{Introdução}

tripé da concepção da universidade pode ser estudado a partir do seu processo histórico, sua interface com a sociedade e suas políticas públicas (Costa; Miguel, 2019). A reflexão sobre as consequências das restrições orçamentárias das universidades públicas que no decorrer de sua trajetória vem ocorrendo com uma frequência cada vez maior é necessária para a compreensão do cenário atual da educação superior pública brasileira, e precisa se expandir para além dos limites da comunidade acadêmica (Barbosa, 2013; Lima; Ferreira Neto; Pompeu, 2019).

As tecnologias, de um modo geral, evoluem para acompanhar o ritmo da sociedade. No ensino, as tecnologias auxiliam por sistemas de informação, plataformas de ensino que suportam aulas on-line e repositório de material didático em diversas mídias, além dos atendimentos síncronos.

Diante desse contexto, apresenta-se resultados de pesquisa que teve por objetivo analisar a percepção do corpo técnico das bibliotecas de uma instituição pública de ensino superior sobre a aceitação da tecnologia de autoatendimento por estes profissionais e o seu papel social no contexto da universidade e das bibliotecas.

$\mathrm{O}$ autoatendimento em bibliotecas é uma alternativa ao contexto atual que permite distanciamento social e minimiza as perdas na força de trabalho. Em bibliotecas que possuem software automatizados, sua implantação é fácil e demonstra um avanço aos serviços ofertados. Nesse contexto, o presente trabalho pode contribuir revelando as crenças dos servidores, fatores motivacionais, dificuldades que podem oferecer respostas e alternativas para aquelas unidades informacionais que buscam implementar suas tecnologias de autoatendimento em bibliotecas - TABs.

\section{Biblioteca na instituição de ensino superior}

As bibliotecas estiveram presentes desde o surgimento das universidades. Inicialmente com copistas e pesquisadores nos mosteiros e, posteriormente, organizadas conforme as disciplinas ofertadas pela instituição mantenedora. É um setor que acompanha a evolução das instituições e aprimora suas práticas regularmente. Conforme Burke (2003), as bibliotecas passaram por uma "reestruturação, em parte como resultado de mudanças na organização das universidades, mas também como resultado da multiplicação de livros" (p. 97), devido à invenção da imprensa, e atualmente, ao uso de tecnologias.

Como parte integrante da universidade, a biblioteca recebe a missão de oferecer à população onde está inserida serviços que impactem em seu cotidiano. A função social deste espaço abarca outras esferas como a disseminação da informação, o fomento das atividades desenvolvidas na instituição e o estímulo ao pensamento crítico, sendo assim é um local possível de transformação social ao preservar os registros da coletividade, e despertar um sentimento de identidade entre os indivíduos (Salcedo; Lima, 2018).

Muitas instituições instauram políticas institucionais que fomentem à área das bibliotecas, como exemplo, um percentual do orçamento da instituição destinado à expansão do acervo, seja em materiais físicos ou em meio eletrônico. A área tecnológica também possui incentivo em algumas instituições que estabelecem políticas com diretrizes para inovação e proteção da propriedade intelectual. 
As demandas de trabalho nas bibliotecas envolvem, desde 0 atendimento aos usuários - empréstimos, devoluções, levantamentos bibliográficos, auxílio na formatação de trabalhos acadêmicos e elaboração de fichas catalográficas -, até o remanejamento de acervo devido ao constante crescimento do acervo. O processamento técnico é uma atividade que engloba a catalogação, classificação, indexação e etiquetagem/carimbagem dos livros. Por ser uma atividade que requer atenção, é uma das atividades mais intensas realizadas pelo bibliotecário.

O desenvolvimento de tecnologias que mantenham o funcionamento de setores como as bibliotecas é indispensável à manutenção dos serviços aos seus usuários. Parte desse compromisso social de formação dos alunos e da comunidade, ocorre por meio da oferta e disponibilização de materiais bibliográficos aos usuários.

Outro fato é a redução gradual do orçamento das universidades públicas pelo Estado, principalmente pela não substituição de servidores que se aposentam o que acarreta a redução do quadro de pessoal, desta forma sobrecarregando servidores, aumentando a quantidade de trabalhadores terceirizados e em decorrência de toda a carga laboral das atribuições e da necessidade de um bom desempenho, o trabalhador é exaurido prejudicando a sua condição de saúde (Han, 2017).

Nesse contexto, as bibliotecas passam a buscar na inovação tecnológica meios para aumentar e melhorar o atendimento aos usuários (Guillem et al., 2013). De outro modo, as tecnologias não superam todos os desafios do atendimento em bibliotecas, por exemplo a interação pessoal dos usuários com os atendentes, muitas vezes demandados pelos estudantes (Cossich, 2014).

Como identificado por Messias et al. (2014), a implantação e uso nas bibliotecas de tecnologias de autoatendimento implica na indução à maior autonomia, praticidade e privacidade. Wing (2019) destaca o histórico do autoatendimento como mecanismo de liberdade, no qual o usuário da biblioteca pudesse acessar obras bibliográficas tidas como revolucionárias ou inadequadas sem o risco de perseguição. Ainda atualmente, o autoatendimento permite ao usuário escolher e retirar obras sem o constrangimento e a censura velada de um atendente humano, o que pode contribuir para a educação sexual, planejamento familiar, além do desenvolvimento de diversas outras competências e habilidades com autonomia e independência do usuário.

O serviço de autoatendimento em bibliotecas propõe a autonomia, agilidade e segurança dos usuários na realização de empréstimos e devoluções dos materiais, pode ainda minimizar a redução das equipes e, no atual momento pandêmico, auxilia no distanciamento social. O uso da tecnologia de autoatendimento em bibliotecas para empréstimo e devolução permite a execução das atividades sem a interferência do profissional, implicando na indução à maior autonomia, praticidade, privacidade e segurança. A operacionalização dessas atividades emprega software de empréstimos, um hardware e monitor, além de tecnologia como a RFID, uma etiqueta inteligente contendo um microchip que armazena os dados de identificação da obra (Messias et al., 2014).

A abordagem do comportamento dos usuários pode ocorrer por diversas dimensões teóricas (Miles, 2012), pelas quais pode-se identificar fatores explicativos que contribuem ou prejudicam o acesso e interação à essas tecnologias. Entre essas visões teóricas, destacam-se as visões da psicologia comportamental de grupos, com as teorias do comportamento racional, do comportamento planejado e as distintas versões do modelo 
de aceitação de tecnologia (Ajzen; Fishbein, 1985; Ajzen, 1991; Venkatesh et al., 2012). Entre esses fatores explicativos, pode-se agrupar, por exemplo, em variáveis de expectativa de desempenho, expectativa de esforço, influência social e condições facilitadoras inicialmente como influenciadores da intenção comportamental, que passou a incorporar três novos construtos ao modelo inicial, os quais a motivação hedônica, o valor do preço e o hábito (Chaves et al., 2021).

\section{Metodologia}

Este estudo é classificado como estudo exploratório pois foi desenvolvido com objetivo de proporcionar uma visão geral e aproximada de determinado assunto de forma metódica, além de propiciar novos enfoques sobre o assunto; assim seus resultados podem formar a base para futuras investigações (Walliman, 2001). Possui abordagem qualitativa, consoante coleta de dados e explicações de conceitos (Perovano, 2016).

Essa abordagem decorre da busca por respostas padronizadas de concordância e discordância a afirmações fundamentadas na teoria apresentada, por meio quantitativo para as distintas alternativas possíveis. Ainda assim, são apresentadas questões abertas que visam capturar percepções diversas que permitam perceber as crenças pessoais do grupo de respondentes e a interpretar os significados da distribuição das respostas quantitativas.

A escolha desta metodologia decorreu por propiciar o entendimento de concepções por parte da amostra estudada e possibilitar o dimensionamento das opiniões dos respondentes. Na busca por respostas que atendessem o objetivo proposta da pesquisa, o instrumento foi desenvolvido a partir da leitura e reflexão sobre a literatura apresentada no referencial teórico, sob as dimensões de utilidades, fatores influenciadores, e aspectos sociais do trabalho e das tecnologias. As perguntas presentes no questionário são apresentadas no quadro 1.

Quadro 1 -

Perguntas elencadas no questionário da pesquisa.

\begin{tabular}{|c|l|c|}
\hline Item & \multicolumn{1}{|c|}{ Enunciado/Questão } & Parâmetros \\
\hline 1 & As TABs promovem a autonomia do estudante. & Likert 5pts \\
\hline 2 & As TABs implicam em praticidade ao estudante. & Likert 5pts \\
\hline 3 & As TABs implicam em privacidade ao estudante. & Likert 5pts \\
\hline 4 & $\begin{array}{l}\text { Quais os fatores que podem influenciar positivamente os } \\
\text { usuários a utilizar as TABs? }\end{array}$ & Aberta \\
\hline 5 & $\begin{array}{l}\text { Quais os fatores que podem influenciar negativamente os } \\
\text { usuários a utilizar as TABs? }\end{array}$ & Aberta \\
\hline 6 & $\begin{array}{l}\text { O uso das TABs pode auxiliar ou prejudicar a experiência dos internos e externos? Caso sim, comente por favor. } \\
\text { usuários }\end{array}$ & Likert 5pts \\
\hline 7 & As TABs beneficiam principalmente os usuários da biblioteca. \\
\hline 8 & $\begin{array}{l}\text { As TABs beneficiam principalmente o corpo técnico da } \\
\text { biblioteca. }\end{array}$ & Likert 5pts \\
\hline 9 & $\begin{array}{l}\text { As TABs contribuem para o aprendizado e desenvolvimento } \\
\text { pleno dos estudantes. } \\
\text { As TABs alinham-se à uma lógica neoliberal. }\end{array}$ & Likert 5pts \\
\hline 10 & $\begin{array}{l}\text { O corpo técnico da biblioteca corre o risco de ser substituído } \\
\text { por TABs. }\end{array}$ \\
\hline 11 &
\end{tabular}




\begin{tabular}{|c|l|c|}
\hline 12 & $\begin{array}{l}\text { Na possibilidade desta substituição, você percebe vantagens } \\
\text { e/ou desvantagens? Comente por favor. }\end{array}$ & Aberta \\
\hline 13 & $\begin{array}{l}\text { Quais as principais dificuldades que você percebe para } \\
\text { implantação de TABs na biblioteca em que você trabalha? }\end{array}$ & Aberta \\
\hline 14 & $\begin{array}{l}\text { Você acredita que as TABs promoveriam um ambiente de } \\
\text { segurança para o acervo na biblioteca em que você trabalha? }\end{array}$ & Aberta \\
\hline
\end{tabular}

Fonte: autores (2021).

Além das variáveis de interesse, foram coletadas variáveis demográficas ou de controle para melhor conhecimento da amostra, sendo o gênero, tempo de cargo e o tipo de cargo. O questionário foi validado por três bibliotecários, com a titulação de mestrado, e um pesquisador-doutor da área de ciências sociais aplicadas. A população-alvo da pesquisa foi definida pela lotação dos servidores, sendo composta pelo conjunto de servidores lotados nas 32 bibliotecas da instituição de ensino que foi objeto da pesquisa.

Os dados foram coletados entre os dias 10 e 23 de agosto de 2021, por meio de questionário aplicado com 0 uso da plataforma SurveyMonkey, enviado por disponibilidade para 87 servidores de uma instituição de ensino superior do Estado do Paraná. A amostra final resultou em 27 respostas completas, cujos respondentes são majoritariamente do sexo feminino e ocupam cargos de nível superior. O perfil é apresentado na tabela 1.

Tabela 1 -

Perfil dos participantes.

\begin{tabular}{l|c|l|c}
\hline Gênero & Qtd. & $\begin{array}{l}\text { Tempo no cargo (média de } \\
\text { anos) }\end{array}$ & 9,02 anos \\
\hline Feminino & 22 & Cargo & Qtd \\
\hline Masculino & 4 & C - Auxiliares e assistentes & 7 \\
\hline Outro / Prefiro não responder & 1 & E - Analistas / bibliotecários & 20 \\
\hline Total & 27 & Total & 27 \\
\hline
\end{tabular}

Fonte: autores (2021).

Os resultados obtidos a partir da percepção dos respondentes quanto às TABs estão demonstrados nos gráficos e tabelas seguintes. Os gráficos foram elaborados de acordo com as análises estatísticas desta pesquisa.

\section{Utilidades promovidas pelo uso das TABs aos usuários}

Inicialmente, foram aplicadas questões relacionadas às utilidades promovidas pelo uso das TABs para seus usuários, para aferir a percepção dos profissionais em exercício nas bibliotecas, nas dimensões de autonomia, praticidade e privacidade. Quanto à promoção da autonomia para o estudante, não houve discordância dentro da escala de Likert utilizada, sendo que $81 \%$ responderam concordar com esta promoção e os demais se manifestaram indiferentes.

Quanto à promoção da praticidade, 16 respondentes afirmaram concordar plenamente com esta característica do uso de TABs. Não foi averiguada resposta discordantes a esta utilidade. Já a característica da privacidade do usuário gerou maior 
discrepância nas respostas, tendo um participante rejeitado totalmente essa utilidade da promoção da privacidade e nove informando indiferença, porém, ainda assim, 17 participantes concordam com esta característica. O gráfico seguinte demonstra a respostas obtidas.

Gráfico 1 -

Características das tecnologias de autoatendimento em bibliotecas.

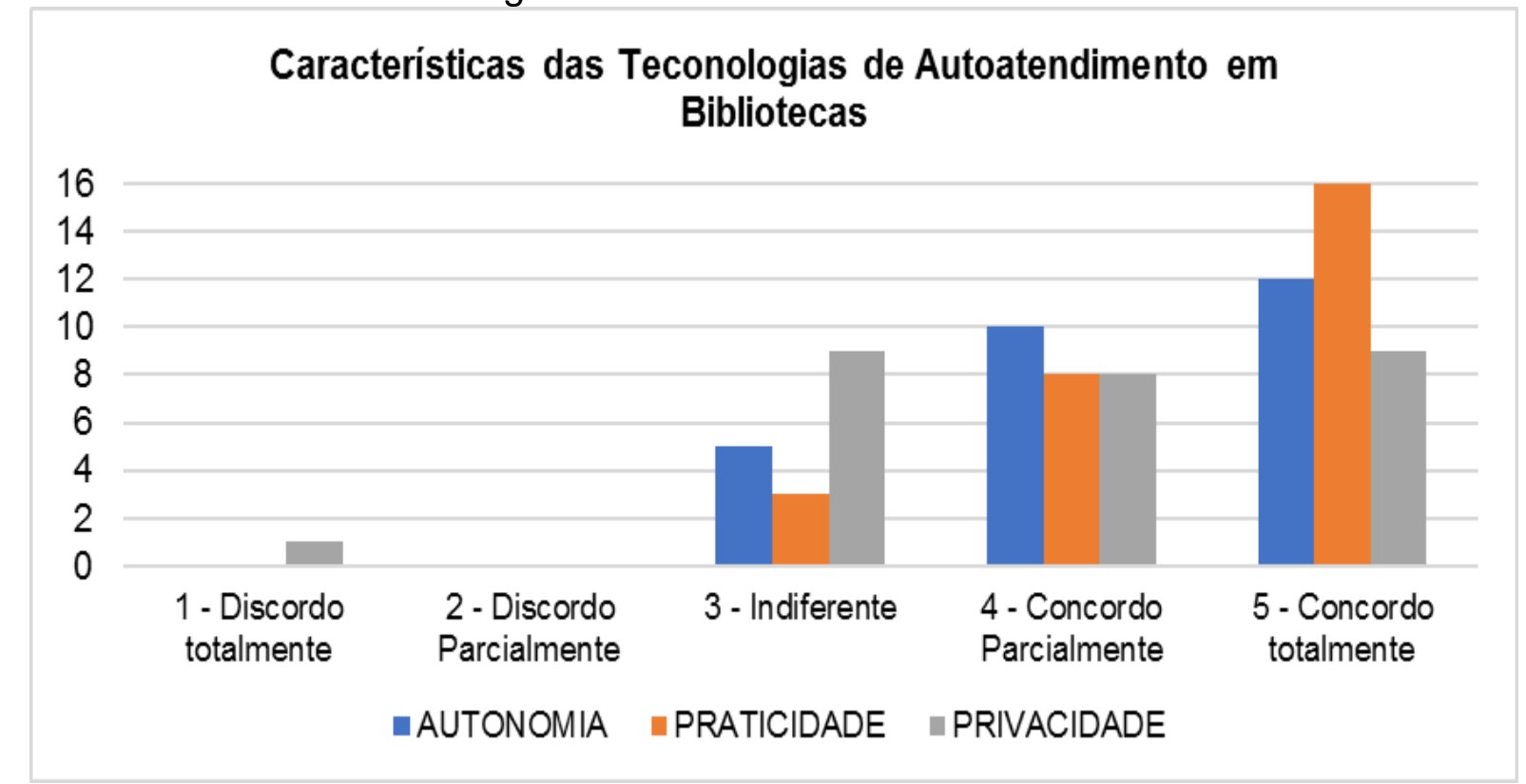

Fonte: autores (2021).

Essas percepções reforçam as indicações de Messias et al. (2014), de que as TABs induzem à maior autonomia, praticidade e privacidade no uso dos serviços da biblioteca. São características que podem ser fomentadas pela equipe do setor para quebrar barreiras no uso de tecnologias que são cada vez mais usuais no dia-a-dia da sociedade. Essas utilidades, embora contribuam para a experiência de uso das bibliotecas, contribuem indiretamente com a formação do usuário pois resulta em acesso ao conteúdo em maior quantidade, e também em qualidade (Wing, 2019).

\section{Fatores motivacionais ao uso das TABs}

Para identificar como é a percepção da equipe das bibliotecas sobre os fatores que podem influenciar positiva ou negativamente os usuários das bibliotecas a utilizarem o serviço de autoatendimento, foram utilizadas duas questões abertas questionando tais percepções. As respostas apresentadas pelos respondentes foram analisadas e categorizadas de acordo com os tipos de influências apresentadas, em categorias e classes relacionadas, dentro de cada grupo de elementos: influências positivas e negativas, as quais são descritas nos quadros seguintes. 
Quadro 2 -

Influências positivas no uso de TABs.

\begin{tabular}{|c|c|c|}
\hline Utilidades ao usuário & Requisitos & Benefícios à unidade \\
\hline $\begin{array}{l}\text { Menor tempo de espera } \\
\text { para atendimento; } \\
\text { Privacidade; } \\
\text { Autonomia; } \\
\text { Comodidade. }\end{array}$ & $\begin{array}{l}\text { Divulgação do uso das } \\
\text { TABs; } \\
\text { Auxílio no uso das TABs; } \\
\text { Usabilidade. }\end{array}$ & $\begin{array}{l}\text { Distanciamento Social } \\
\text { Dinamismo; } \\
\text { Diminuição de custos; } \\
\text { Responsabilidade do } \\
\text { usuário. }\end{array}$ \\
\hline
\end{tabular}

Fonte: autores (2021).

Entre as influências positivas, que tendem a motivar as partes envolvidas a motivarem seus usuários, destacam-se categorias relacionadas às utilidades aos usuários, o atendimento aos requisitos de qualidade e asseguração das TABs e os benefícios à unidade da biblioteca, que corroboram a possibilidade de distintas visões teóricas propostas por Miles (2012). Indicações dos respondentes de que as TABs resultam em mais agilidade e privacidade relacionam-se à expectativa de desempenho ou utilidade da tecnologia, enquanto a autonomia e comodidade relacionam-se às condições facilitadoras (Venkatesh et al., 2012).

Os requisitos necessários para o funcionamento das TABs podem ser analisados diante da variável de expectativa de esforço pela ausência dessas características na tecnologia. Inerente ao processo de construção de uma funcionalidade tecnológica, outros grupos podem obter benefícios (Chaves et al., 2021), como é o caso do corpo técnico das bibliotecas que, por meio dessas TABs, podem implantar distanciamento social, dinamismo e foco em outras tarefas, redução de custos e maior autonomia do usuário, conforme relatado pelos respondentes.

Quadro 3 -

Influências negativas no uso de TABs.

\begin{tabular}{|l|l|}
\hline \multicolumn{1}{|c|}{ Fatores estruturais } & \multicolumn{1}{c|}{ Fatores e crenças pessoais } \\
\hline Quedas de energia; & Rejeição à tecnologia; \\
Problemas de conectividade; & Medo de errar no manuseio; \\
Lentidão e falhas do equipamento; & Ausência de interação e vínculos com os \\
Ferramenta não intuitiva & atendentes; \\
& Desconhecimento sobre as TABs. \\
\hline
\end{tabular}

Fonte: autores (2021).

Uma das principais preocupações dos respondentes refere-se à falta de interação humana decorrente da mediação das TABs. O bibliotecário de referência e os atendentes são fundamentais no esclarecimento de dúvidas e promoção de outros serviços e no auxílio na busca da informação demandada, percepção que é destacada por vários respondentes.

"Muitos usuários talvez gostariam de ser atendido por um servidor da biblioteca e mesmo porque o servidor pode esclarecer outras dúvidas ou até mesmo incentivar para outros serviços. Não desmerecendo o autotendimento, acredito que ele é necessário, mas o atendimento por uma pessoa da biblioteca também é importante e mensura outros valores como a empatia que a máquina não será capaz de promover. (R02) 
"Não criar vínculo com os trabalhadores da biblioteca e interações que refletem em aprendizados mútuos. (R19)

Essa crítica vai ao encontro de Cossich (2014), sobre a expectativa de que o serviço de referência supera a prestação de serviços específicos e inclui a percepção de que o tratamento personalizado e diferenciado são a razão da existência de uma biblioteca. Nesta linha de necessidade de interação entre os usuários é possível refletir sobre a possibilidade de novas tecnologias interativas, como chat-box com instrumentos de inteligência artificial, que podem minimizar parte destas dificuldades. Além disso, o serviço de autoatendimento pode ser uma facilidade empregada de forma concomitante ao serviço de atendimento tradicional, como já ocorre em algumas bibliotecas, onde o usuário pode escolher o atendimento pessoal ou ao autoatendimento.

Outra preocupação bastante referida é a conectividade da internet e da energia, com quedas durante o processamento e, até mesmo, falhas técnicas em equipamentos, o que pode gerar um atendimento ineficiente na rotina de empréstimo ou devolução. É importante destacar que o fator considerado mais frequentemente como positivo é a diminuição de filas de atendimento, principalmente em horários de grande demanda. Além disso, a pandemia causada pela Covid-19 requer distanciamento social e o serviço de autoatendimento corrobora com esta situação.

\section{Utilidades no uso do autoatendimento em bibliotecas}

As entrevistas buscaram identificar os principais beneficiários do serviço de autoatendimento e relação com o processo de aprendizagem do usuário. As respostas da amostra de servidores das bibliotecas indicam que, tanto o corpo técnico, quanto os usuários, que retiram o acervo bibliográfico na forma de empréstimo, podem ser beneficiados pelas TABs, o que alcança inclusive benefício ao processo de aprendizagem, conforme é demonstrado por meio do uso de estatística descritiva na tabela 2.

Tabela 2 -

Percepção de utilidade das TABs.

\begin{tabular}{l|c|c|c|c|c|c}
\hline \multicolumn{1}{c|}{ Categorias de concordância } & \multicolumn{2}{|c|}{$\begin{array}{c}\text { Benefício ao } \\
\text { corpo técnico }\end{array}$} & \multicolumn{2}{c|}{$\begin{array}{c}\text { Benefício aos } \\
\text { usuários }\end{array}$} & \multicolumn{2}{c}{$\begin{array}{c}\text { Benefício à } \\
\text { aprendizagem }\end{array}$} \\
\hline 1 - Discordo totalmente & 3 & $11,1 \%$ & 0 & $0,0 \%$ & 2 & $7,4 \%$ \\
\hline 2 - Discordo parcialmente & 1 & $3,7 \%$ & 3 & $11,1 \%$ & 3 & $11,1 \%$ \\
\hline 3 - Indiferente & 6 & $22,2 \%$ & 8 & $29,6 \%$ & 9 & $33,3 \%$ \\
\hline 4 - Concordo parcialmente & 12 & $44,4 \%$ & 8 & $29,6 \%$ & 8 & $29,6 \%$ \\
\hline 5 - Concordo totalmente & 5 & $18,5 \%$ & 8 & $29,6 \%$ & 5 & $18,5 \%$ \\
\hline Total & 27 & $100,0 \%$ & 27 & $100,0 \%$ & 27 & $100,0 \%$ \\
\hline \multicolumn{1}{|c|}{ Fonte: autores (2021). } & & & & &
\end{tabular}

Dentre os respondentes, $63 \%$ concordaram que o corpo técnico é o principal beneficiado com o uso de TABs. Tal percentual retrata a dificuldade das equipes de bibliotecas em atender todas as demandas do setor, principalmente em unidades que 0 quadro de pessoal do setor é restrito e o acúmulo de atividades atrapalha na qualidade e agilidade dos serviços oferecidos. Neste contexto, a visão de Han (2017) é fortalecida ao situar o trabalhador numa situação de multitarefa. 
A possibilidade de benefício ao usuário no uso das TABs, apesar de ter recebido grande parte de concordância, gerou respostas mais fragmentadas. Possivelmente em conformidade com a questão social da biblioteca no atendimento e compreensão da demanda do usuário. As tecnologias ainda não conseguem gerar empatia, por mais que esteja se tornando comum a utilização de inteligência artificial em muitos serviços de atendimento.

Em referência ao uso de TABs auxiliar ou prejudicar a experiência dos usuários, foi destaque que a maior parte dos respondentes acredita que o uso pode auxiliar a experiência na biblioteca, principalmente no que se refere à privacidade, autonomia e otimização do tempo. Porém, muitos se preocuparam com o caráter humanístico e social da biblioteconomia, em que a interação humana é indispensável para sanar as necessidades informacionais dos usuários, sendo primordial que o serviço de autoatendimento seja uma opção a mais ao usuário, não substituindo a possibilidade do contato interpessoal.

A possibilidade da aprendizagem escolar e o desenvolvimento dos estudantes ser beneficiada pelo uso das TABs obteve percepção predominantemente positiva na proporção de $49 \%$ dos respondentes, ainda que parcela significativa (33\%) se mostraram indiferentes e apenas 19\% refutaram esta contribuição. A análise das respostas mitiga a existência de relação direta, mas abre a possibilidade que estas ações indiquem uma relação indireta, como o fato do acesso maior à bibliografia fomentar o aprendizado, além de contribuir com a inclusão social dos usuários no que diz respeito ao uso de tecnologias.

\section{Aspectos sociais no uso de TABs}

A utilização de serviços de autoatendimento nas bibliotecas pode ser interpretada sob diferentes óticas, assim como gerar distintas percepções nos indivíduos. Os avanços tecnológicos inegavelmente oferecem benefícios à sociedade, ao desenvolvimento social, às condições de trabalho, entretanto, sua introdução nas relações sociais pode gerar conflitos, principalmente quando empregada apenas visando o ganho financeiro para as organizações.

Diante desses potenciais conflitos, analisou-se as questões indagadas aos respondentes sobre se a inclusão das TABs nas bibliotecas é percebida como uma estratégia neoliberal, visto que a inserção de postos de autosserviço pode gerar a supressão de cargos de servidores. Também foi questionado diretamente aos servidores sobre a percepção em relação a possibilidade de serem substituídos por TABs.

Nesse contexto, predominaram respostas com a percepção de indiferença ao conceito de que as TABs se alinham ao conceito neoliberal, enquanto maior parte discorda do risco de serem substituídos por essas tecnologias. A dispersão das respostas dos entrevistados é demonstrada no gráfico 2. 
Gráfico 2 -

Distribuição das percepções dos aspectos sociais do trabalho.

\section{Aspectos Sociais do Trabalho}

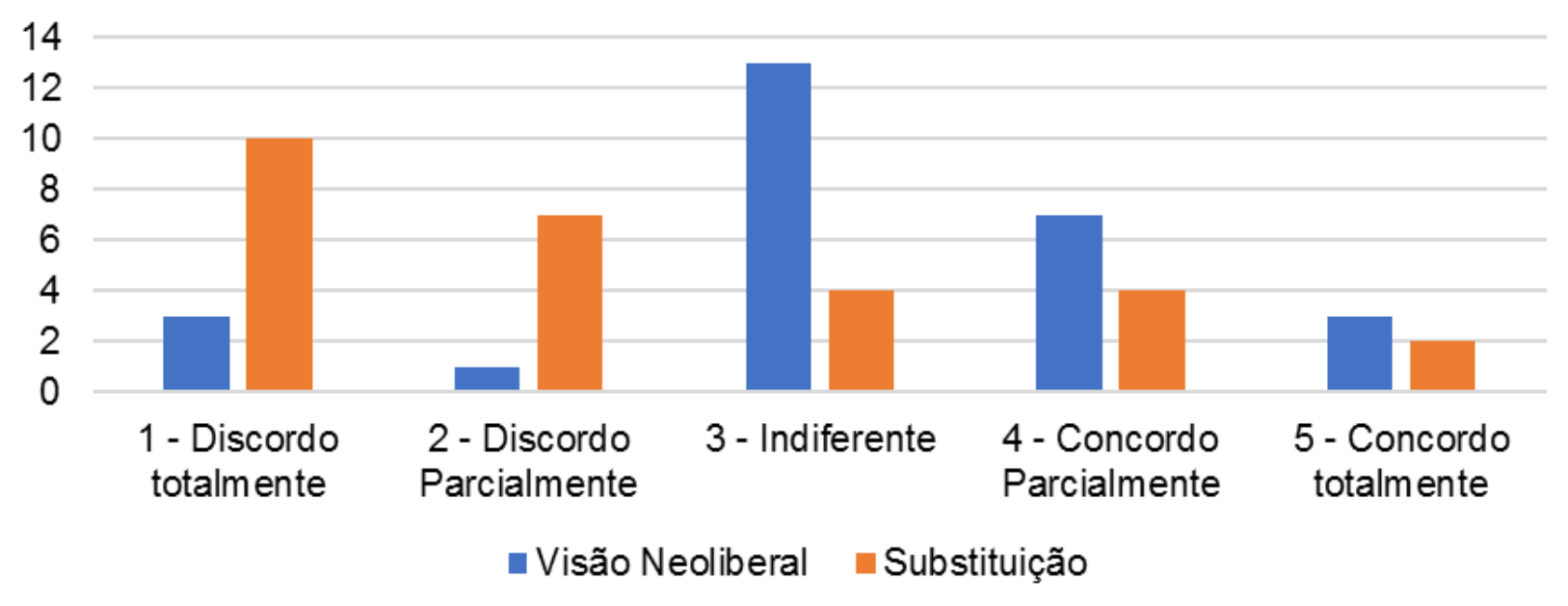

Fonte: autores (2021).

Os respondentes, na sua maioria, posicionaram-se pela indiferença das TABs em relação à ótica neoliberal, com seis respondentes indicando discordância e dez indicando concordância em maior ou menor grau. Os conflitos gerados pela ótica neoliberal no espaço da educação englobam uma visão menos social e mais mercantilista do processo de formação dos estudantes, o que possivelmente não seja percebido por conta de uma inserção tecnológica mais pontual no ambiente laboral.

O trabalhador nas instituições de ensino superior tem sido pressionado a realização de demandas que muitas vezes não permitem momentos de reflexão sobre o andamento das atividades fundamentais dos setores aos quais estão lotados. Sob o enfoque da possibilidade de os servidores serem substituídos pelos terminais de autoatendimento, a maior parte (17\%) discorda desta possibilidade, o que evidencia o cunho social da atividade da biblioteca, enquanto apenas seis respondentes afirmaram que isso poderia ocorrer.

Tabela 3 -

Percepção de utilidade das TABs.

\begin{tabular}{l|c|c|c|c}
\hline \multicolumn{1}{c|}{$\begin{array}{c}\text { Categorias de } \\
\text { concordância }\end{array}$} & \multicolumn{2}{c|}{$\begin{array}{c}\text { Visão social das TABs } \\
\text { (Neoliberal) }\end{array}$} & \multicolumn{2}{c}{$\begin{array}{c}\text { Substituição do trabalhador } \\
\text { pela tecnologia }\end{array}$} \\
\hline 1 - Discordo totalmente & 3 & $11,1 \%$ & 10 & $37,0 \%$ \\
\hline 2 - Discordo parcialmente & 1 & $3,7 \%$ & 7 & $25,9 \%$ \\
\hline 3 - Indiferente & 13 & $48,1 \%$ & 4 & $14,8 \%$ \\
\hline 4 - Concordo parcialmente & 7 & $25,9 \%$ & 4 & $14,8 \%$ \\
\hline 5 - Concordo totalmente & 3 & $11,1 \%$ & 2 & $7,4 \%$ \\
\hline Total & 27 & $100,0 \%$ & 27 & $100,0 \%$ \\
\hline
\end{tabular}

Fonte: autores (2021).

Alguns respondentes apresentaram preocupação caso houvesse a substituição total dos atendentes por TABs, haja vista a diminuição de postos de trabalho e consequentemente a perda da interação humana no sentido de auxiliar o usuário. 0 \begin{tabular}{l|l|l|l} 
Regae: Rev. Gest. Aval. Educ. & Santa Maria & v. 11 & n. 20
\end{tabular}

\begin{tabular}{|l|l|r}
\hline 20 & e67813, p. 1-14 & 2022 \\
\hline
\end{tabular}


predomínio das respostas direcionou a ausência do risco de substituição foi acompanhado da perspectiva que esta substituição pudesse ocorrer, mas que seria uma substituição pontual, uma inovação que teria como principal vantagem a otimização do tempo de trabalho para outras demandas do setor. Essa perspectiva pode ser exemplificada na resposta dos respondentes:

(R15): O atendimento não é a única tarefa desempenhada pela equipe da biblioteca. Para que o livro esteja disponível para empréstimo são necessários os processos de aquisição, processamento técnico e preparo físico dos livros para que cheguem à prateleiras e possam ser recuperados em sistema pelo usuário. Ademais, faz-se necessário o auxilio da equipe da biblioteca no uso do sistema e na solução de eventuais problemas técnicos.

(R07): Vantagens, pois, o servidor pode empenhar-se em outras atividades do setor.

A análise sobre as reflexões para implantação das TABs foi percebida no questionamento sobre as dificuldades para essa implantação. Foi evidenciada a preocupação da equipe das bibliotecas no que se refere à questão orçamentária para a implementação e manutenção de equipamentos para autoatendimento. Do mesmo modo, foi expresso que a gestão da instituição, em alguns casos, pode não demonstrar interesse em investimentos na biblioteca, conforme corrobora o respondente 24: "Falta de compreensão do papel das bibliotecas por parte de algumas/uns gestoras/es para investimento em TABs."

Cabe salientar que muitas respostas tiveram como preocupação a capacitação dos usuários em relação à implantação, sendo que tal cuidado é fundamental na efetivação de uso de qualquer tecnologia e deve ser planejado com minúcia para minimizar os receios dos usuários e fomentá-los ao uso.

Quanto à reflexão sobre a segurança do acervo com a utilização das TABs, predominantemente, foi aferido que não haveria problemas de extravios, porém, foi ressaltado que a implantação de TABs envolve o investimento em câmeras de monitoramento, sistema de segurança mais moderno que envolva tecnologias com uso de antenas de segurança e chips/etiquetas magnéticas em cada exemplar.

\section{Conclusões}

As vantagens da utilização das TABs foram predominantes nesta pesquisa, sendo perceptível nas respostas as perguntas abertas algum medo de substituição e perda do caráter social desempenhado pelas bibliotecas. Cabe destacar que, apesar da pesquisa se restringir a uma instituição pública de ensino superior, os respondentes se permitiram refletir sobre o uso de TABs em diferentes realidades, ou seja, bibliotecas de diferentes portes, com os mais variados fluxos de usuários.

A partir da análise dos dados e apresentação dos resultados, foi possível atender ao objetivo de averiguar a percepção do corpo técnico das bibliotecas sobre a aceitação da tecnologia de autoatendimento por estes profissionais e o seu papel social no contexto das instituições de ensino. Essa análise oferece a discussão das percepções e crenças 
dos profissionais que atuam nesse ambiente, sendo, portanto, um produto que pode contribuir para o desenvolvimento de estratégias que beneficiem as bibliotecas e suas correspondentes instituições de ensino com determinantes para a implantação de TABs mais adequadas e eficazes para esse ambiente.

Apesar de não relatado nas respostas registradas, é possível que a questão patrimonial do material seja um determinante para o grau de aceitação do tipo de tecnologia proposto. As instituições públicas federais são constantemente auditadas por órgão de controle e, no que diz respeito às bibliotecas, é fundamental a realização de inventários de bens dos livros, tendo em vista serem considerados bens permanentes e, com isso, acarretarem processos administrativos por eventual percentual significativo de extravios. A restrição da amostra à uma única instituição de ensino, apesar de corresponder a 26 bibliotecas setoriais, limita a possibilidade de generalização dos resultados, revelando-se como uma limitação da pesquisa.

\section{Referências}

ADAMCZYK, Willian. Automação pode suprir aposentadoria de 54 mil servidores. Brasília: Emap, 2021. Disponível em: https://enap.gov.br/pt/acontece/noticias/automacao-podesuprir-aposentadoria-de-54-mil-servidores. Acesso em: 31 ago. 2021.

AJZEN, lcek. The theory of planned behavior. Organizational behavior and human decision processes, v. 50, n. 2, p. 1991, 179-211.

BARBOSA, Cesar. Financiamento público das universidades estaduais baianas: restrições orçamentárias, expansão universitária e desenvolvimento local. Salvador: Uneb, 2013. 164f. Tese (Doutorado em Educação e Contemporaneidade). Universidade do Estado da Bahia.

BIANCHETTI, Lucídio; SGUISSARDI, Valdemar. Da universidade à commoditycidade ou de como e quando, se a educação/formação é sacrificada no altar do mercado, o futuro da universidade se situaria em algum lugar do passado. São Paulo: Mercado das Letras, 2017.

BRASIL. Rede federal de educação profissional, científica e tecnológica. Brasília: MEC, 2021.

BÚRIGO, Carla C. D. Universidade pública federal brasileira: democraticamente massificada. REXE: Revista de Estudios y Experiencias en Educación, Concepción/Chile, v. 1, n. 1, 2016, p. 105-124.

BÚRIGO, Carla C. D.; ESPÍNDOLA, Corina M.; SOUZA, Sandra C. de. Universidade: impacto social e o processo de desenvolvimento da educação inclusiva. COLÓQUIO DE GESTIÓN UNIVERSITARIA EM AMÉRICAS, 13, 2013. Anais ... Florianópolis: UFSC, 2013, p. 1-14.

BURKE, Peter. Uma história social do conhecimento: de Gutenberg a Diderot. Rio de Janeiro: Zahar, 2003.

CHAVES, Alice; FLACH, Leonardo; SALLLABERRY, Jonatas. The role of individual values in the behavior of using discount coupons. Revista de Administração da UFSM, Santa Maria, v. 14, n. 3, 2021, p. 568-591.

COSSICH, Marília. Serviço de referência: o que se espera dele? Revista Biblioo, Rio Grande, v. 28, n. 2, 2014, p. 27-36. 
COSTA, Rosa da P. F.; MIGUEL, Marcelo C. Informação, memória institucional e produção acadêmica: o legado da Ufes na Web of Science (2009-2018). Revista de Gestão e Avaliação Educacional, v. 8, n. 17, 2019, p. 1-17.

FRANCHINI, Fernanda; FREITAS, lara S.; ENNSER, Maria Cristina B.; BOZEDA, Mariana G.; FERREIRA, Mariana R. F.; ALEXANDRE, Victor S. Desafios à docência no ensino superior em tempos neoliberais. Revista Gestão \& Políticas Públicas, São Paulo, v. 6, n. 1, 2016, p. 118-139.

GEMELLI, Catia E.; CLOSS, Lisiane Q.; FRAGA, Aline M. Multiformidade e pejotização: (re)configurações do trabalho docente no ensino superior privado sob o capitalismo flexível. REAd. Revista Eletrônica de Administração, Porto Alegre, v. 26, 2020, p. 409-438.

GUILHEM, Cristina B.; TORINO, Ligia P.; TAVARES, Helena. Um olhar sobre inovação em bibliotecas universitárias: desafios e possibilidades. CONGRESSO BRASILEIRO DE BIBLIOTECONOMIA, DOCUMENTAÇÃO E CIÊNCIA DA INFORMAÇÃO, 25, 2013. Florianópolis: CBBD, 2013.

HAN, Byung-chul. Sociedade do cansaço. Petrópolis: Vozes, 2017.

HASKINS, Charles H. A ascensão das universidades. Santa Catarina: Danúbio, 2015.

LIMA, Mariete X. A.; NETO, Macário N. F.; POMPEU, Randal M. Projeto de extensão no ensino superior como prática de responsabilidade social. Regae: Rev. Gest. Aval. Educ., Santa Maria, v. 8, n. 17, 2019, p. 1-12.

MESSIAS, Lucilene C. S.; MORALES, Célia Silva C.; OLIVEIRA, Maith Martins de; ZANIBONI, Maria Marlene; RIBEIRO, Maria Thereza P. Implantação do sistema de autoatendimento na biblioteca da unesp do campus de Bauru: perspectivas de otimização nos serviços de empréstimo e devolução. SEMINÁRIO NACIONAL DE BIBLIOTECAS UNIVERSITÁRIAS, 17, 2014. Anais... São Paulo: SNBU, 2014, p. 1-9.

MILES, Jeffrey A. Management and organization theory: A Jossey-Bass reader. John Wiley \& Sons, 2012.

MOCARZEL, Marcelo M. V. A financeirização da educação privada nas páginas de revista: discursos publicitários sobre a universidade brasileira. Educação \& Sociedade, Campinas, v. 40, 2019, p. 1-19.

PEROVANO, Dalton G. Manual de metodologia da pesquisa científica. São Paulo: Intersaberes, 2016.

RAMOS, Alberto G. A nova ciência das organizações: uma reconceituação da riqueza das nações. Rio de Janeiro: FGV, 1989.

SALCEDO, Diego; LIMA, Igor P. O papel do bibliotecário na prática de preservação da memória institucional: o caso do Espaço Memória da Justiça Federal em Pernambuco. Ágora, Florianópolis, v. 28, n. 57, 2018, p. 314-331.

SANTA ANNA, Jorge; SILVA, Edcleyton Bruno Fernandes da; COSTA, Maria Elizabeth de Oliveira (org.). Biblioteconomia social: possíveis caminhos para construção da cidadania. Belo Horizonte: ABMG, 2018.

SAWICKI, Simone Salete; PAGLIARIN, Lidiane Limana Puiati. Gestão escolar e avaliação em larga escala: realidades, possibilidades e desafios. Regae: Rev. Gest. Aval. Educ., Santa Maria, v. 7, n. 16, 2018, p. 25-39.

SGUISSARDI, Valdemar. Modelo de expansão da educação superior no Brasil: predomínio privado/mercantil e desafios para a regulação e a formação universitária. Educação \& Sociedade, Campinas, v. 29, 2008, p. 991-1022 
SILVA, Bento D. O poder transformador das tecnologias da Informação e da Comunicação (TIC). Portugal: Universidade do Minho, 2016.

VENKATESH, Viswanath; THONG, James YL; XU, Xin. Consumer acceptance and use of information technology: extending the unified theory of acceptance and use of technology. MIS quarterly, Minnesota, p. 157-178, 2012.

WALLIMAN, Nicholas. Your Research Project a step-by-step guide for the first-time researcher. London: Sage, 2001.

WING, Kate. Use of self-service holds in maine public libraries. Public Library Quarterly, Philadelphia, v. 38, n. 1, 2019, p. 85-102.

Bárbara Rocha Bittencourt é estudante no curso de mestrado em Administração Universitária na Universidade Federal de Santa Catarina.

Orcid: https://orcid.org/0000-0001-5435-7441.

Endereço: Rua João Negrão, 1285 - 80230-150 - Curitiba - PR - Brasil.

E-mail: barbararb@gmail.com.

Isaías Scalabrin Bianchi é professor na Universidade Federal de Santa Catarina.

Orcid: https://orcid.org/0000-0001-5480-0642.

Endereço: Rua Eng. Agronômico Andrei Cristian Ferreira, s/n - 88040-900 Florianópolis - SC - Brasil

E-mail: isaias.bianchi@ufsc.br.

Critérios de autoria: Bárbara foi responsável pela coleta, descrição e análise dos dados. Isaías participou da supervisão do planejamento e da revisão do manuscrito. Os autores participaram da redação.

Recebido em 23 de setembro de 2021.

Aceito em 17 de dezembro de 2021.

(c) (i) (s) $\Theta$ 